\title{
EFFECT OF HIGH AND LOW FLEXIBILITY ON AGILITY, ACCELERATION SPEED AND VERTICAL JUMP PERFORMANCE OF VOLLEYBALL PLAYERS
}

\author{
Aruna Gulati', \\ Rita Jain ${ }^{1}$, \\ Anuradha Lehri' ${ }^{2}$, \\ Rajneesh Kumar ${ }^{3 i}$ \\ ${ }^{1}$ Dr., Indira Gandhi Institute \\ of Physical Education \& Sports Sciences, \\ University of Delhi, \\ Delhi, India \\ ${ }^{2}$ Dr., Department of Sports Sciences, \\ Punjabi University Patiala, \\ Patiala, India \\ ${ }^{3}$ Netaji Subhas Southern Centre, Bengaluru, \\ Sports Authority of India,
} India

\begin{abstract}
:
This study aimed to assess the effect of high and low levels of flexibility on key performance indicators of volleyball performance. Eighty-four volleyball players $(\mathrm{n}=84$; mean \pm SD; decimal age: $16.57 \pm 1.51$; height $(\mathrm{cm})$ : $176.23 \pm 8.77$; body mass $(\mathrm{kg}): 66.14 \pm 11.79$ ) were selected for the study. The design of the study was cross-sectional and to measure selected variables i.e. agility, lower body muscular power, and acceleration speed; $6 \times 10$ $\mathrm{m}$ shuttle run, countermovement jump (with arm swing) test and $20 \mathrm{~m}$ sprint test (standing start) were used. To measure the flexibility level of the players, sit and reach test was used. Shapiro-Wilk normality test was conducted to check the distribution of data and the Levine test was applied to check homogeneity of the variance in data. Participants were divided into two groups i.e. High Flexibility Group (HFG) and Low Flexibility Group (LFG) using k-means cluster analysis and independent t-test was applied to find the differences between HFG and LFG. The level of significance was set at $p<0.05$. Results showed statistically significant difference between HFG and LFG in agility, acceleration speed and lower body muscular power and, based on the results, it was concluded coaches should include flexibility training in the regular training programme. The results obtained supported the rationale that baseline flexibility may influence the performance of volleyball players.
\end{abstract}

i Correspondence: email rajneesh.bishnoi32@gmail.com, rajneeshvolleyball@gmail.com 
Keywords: volleyball, flexibility, agility, acceleration speed, vertical jump

\section{Introduction}

Volleyball is one of the popular team sports which is played both indoors and outdoors. In indoor volleyball rallies include intensive actions such as jumping, multidirectional movements, spiking, blocking and striding, and intervals between the rallies include low intensive recovery breaks such as walking and standing (Gabbett et al., 2006; Holmberg, 2013; Kerksick et al., 2018; Marques et al., 2009).

The nature of the game and physiological demands exerted makes it necessary to attain a high level of fitness combined with other factors such as technical, tactical and psychological (Greco et al., 2019; Pradhan, 2017). Research evidence shows that volleyball players require a high level of speed, agility, power, muscular strength and aerobic endurance (Gabbett et al., 2006; Oldenburg, 2015; Pradhan, 2017; Reeser \& Bahr, 2003).

Flexibility, the range motion achievable at a joint or group of joints without getting injured (Gremion, 2005), is considered an important aspect of sports performance, however, its role in each sport varies depending on the nature and demands involved (Rey et al., 2016). It is postulated that high flexibility level has a significant effect on performance, however, studies exploring the relationship of flexibility with sports performance are limited and have heterogeneous results. It is also difficult to generalize this postulation because sports performance is influenced by several internal and external factors (Lee et al., 1989; Singh, 1991).

In Volleyball, high level of lower body muscular power is needed as players have to perform several vertical jumps (Gabbett \& Georgieff, 2007; Kenny \& Gregory, 2006; Ziv \& Lidor, 2010). It is required as players have to perform number of skills that needs jumping such as spiking, blocking, jump set and jump serve (Hedrick, 2007; Newton et al., 2006; Powers, 1996).

Several studies exploring the relationship of flexibility with vertical jumping performance, but results are not homogeneous. In a study, it was found that dynamic stretching significantly improved kinetic variables of vertical jumping in female volleyball players (Kruse et al., 2015). In another study, positive effects of the stretching on jumping performance were also reported (Palaniappan \& Deivendran, 2013). In contrast to the above findings, there is number of studies that do not agree with the above results (Church et al., 2001; Cornwell et al., 2001; Little \& Williams, 2006; Walsh, 2017; Young \& Behm, 2003).

In volleyball, high-level reaction and acceleration speed are required as players have to react very quickly because the ball travels at high velocity and the volleyball court is also relatively small in the area which inhibits them to attain maximal speed (Johnson et al., 2010). However, researches on the relationship of flexibility with speed and agility are also limited and have conflicting results (Alikhajeh et al., 2012; Alipasali et al., 2019; Bazett-Jones et al., 2008; Fletcher \& Jones, 2004; Herman \& Smith, 2008). In studies, it has been found that dynamic stretching is effective in the improvement of agility 
performance (Taleb-beydokhti \& Haghshenas, 2015; Van Gelder \& Bartz, 2011). On the other hand, Bishop \& Middleton, (2013) concluded that there are no significant differences in the performance of speed, agility and jump after warm-up using dynamic and dynamic cum static protocols.

Though stretching exercises in the warm-up are common practice in volleyball (Alipasali et al., 2019), but the relationship of flexibility with volleyball performance is not fully explored. Agility, acceleration speed and vertical jump are key determinants of volleyball performance (Gabbett et al., 2006; Marques et al., 2009; Newton et al., 2006; Oldenburg, 2015; Pradhan, 2017; Reeser \& Bahr, 2003). Therefore, this study is an attempt to assess the effect of high and low levels of lower back and hamstring flexibility on agility, acceleration speed and vertical jump among young volleyball players.

\section{Methodology}

\subsection{Participants}

A total of eighty-four male young volleyball players $(n=84$; mean $\pm S D$; decimal age: 16.57 \pm 1.51 ; height $(\mathrm{cm})$ : $176.23 \pm 8.77$; body mass $(\mathrm{kg})$ : $66.14 \pm 11.79)$, undergoing regular training were selected for the study. All the participants were healthy and physically fit with no history of injury in the past six months. The participants were informed in detail about the nature of the study and investigational procedures, and all the participants have voluntarily given their consent to be the part of this study.

\subsection{Design}

This study used a cross-sectional designed to assess the effect of high and low flexibility (lower back and hamstring) on agility, acceleration speed and vertical jump performance. To measure selected variables i.e. agility, lower body muscular power, and acceleration speed; $6 \times 10 \mathrm{~m}$ shuttle run, countermovement jump (with arm swing) test and $20 \mathrm{~m}$ sprint test (standing start) were used, respectively. To measure the level of flexibility Forward bend and reach test was used. The selected tests were administrated during the precompetition phase in two experimental sessions. The first experimental session included the measurement of basic anthropometric, flexibility, and agility measurement of participants. On the second experimental session, vertical jump and acceleration speed performances were recorded.

To avoid potential diurnal effects on the performance, tests were conducted at the same time in every session. A day between two experimental sessions was kept as a regular training day with no heavy training. All the participants were informed in advance about the testing procedures and two days before the testing, two sessions were kept to familiarize them with the testing protocols. In both familiarization and testing (experimental) sessions, a proper warm-up for 20 minutes was performed by the participants under the supervision of the coach. The warm-up consisted of 05 minutes of static stretches of major muscles of the lower and upper body followed by low-intensity 
aerobic activities (jogging, running and multilateral movements) for 10 minutes and at last total body dynamic stretches for 05 minutes.

To minimize the training-induced fatigue, the preceding session of the first testing session was kept for active recovery and it was also ensured that there should be no heavy training on the day falling between the two testing sessions. To avoid the effect of the daily routine on the test performance the players were asked to take proper rest and refrain themselves from unnecessary activities apart from their daily routine. Besides, players were encouraged to eat healthy and nutritious food, and intake of acute performance-enhancing substances before and during testing were barred.

\section{Procedure}

\subsection{Anthropometric Measurements}

On the first experimental session, anthropometric measurements of participants i.e. height, body mass and standing vertical reach were taken before warming up. The height of the participants was measured with a standardized Anthropometer (GPM-100) with an accuracy of $0.001 \mathrm{~m}$. Standing vertical reach was measured using a standardized scale mounted on the wall with an accuracy of $0.01 \mathrm{~m}$. To measure the body weight of participants a standardized weighing scale (Omron HN-286) with an accuracy of $0.01 \mathrm{~kg}$ was used.

\subsection{Flexibility Measurement}

Post-warm-up, the flexibility of the lower back and hamstring was measured with sit and reach test (Wells \& Dillon, 1952) using a standardized sit-and-reach box. Mayorga-Vega et al., (2014) reported that the classic Sit and Reach Test was a better indicator of hamstring flexibility as compared to other sit and reach tests (modified sit and reach test) and when it is not possible to use angular flexibility tests. The participants were asked to sit on the floor barefoot with legs fully extended and placed against the sit-and-reach box. Then they were asked to extend their arms and place the palms (facing down) on the scale and slide forward as far as possible and hold the position at a maximal distant point for a minimum of 03 seconds. They were given three chances and the best performance was taken as the final score.

\subsection{Agility Measurement}

Agility was measured using the $6 \times 10 \mathrm{~m}$ shuttle run test (SAI, 2016). In this test, two parallel lines with a $10-\mathrm{m}$ distance were marked on the plain surface. Participants were asked to stand behind the starting line in the ready position. On the signal, they were asked to run fast and touch the other line (with one hand) and then come back to the starting line and touch it. They were told to repeat this procedure for three-time (total six shuttles) with maximum speed. The test performance was measured nearest to 0.01 second. With optimum recovery time, total two attempts were given, and the best performance was taken as final score. 


\subsection{Vertical Jump Measurement}

On the second experimental day, lower body muscular power and acceleration speed were measured. After following the same warm-up protocol, lower body muscular power was measured using countermovement jump with arm swing (Acero et al., 2012) on a wall-mounted calibrated vertical jump tester (Tandem Sport). The participants were asked to stand beside the device and jump as high up as possible with arm swing but without taking any approach or step and touch the highest point on the device. Three attempts were given to each participant and the final score was obtained by subtracting the standing vertical reach from their best vertical jump performance.

\subsection{Speed Measurement}

The acceleration speed of participants was measured using a 20-m Sprint test with standing start. For the test, a straight lane of the $400-\mathrm{m}$ track was used where starting and finishing points were marked with a distance of $20 \mathrm{~m}$. The participants were asked to run with maximum speed from starting point to finishing point after auditory signal and performance nearest to the 0.01 second, was measured. With optimal recovery, two attempts were given, and the best timing was taken as the final score.

\section{Statistics Applied}

First, descriptive statistic, mean and standard deviation (SD) were calculated. The Shapiro-Wilk normality test was conducted to check whether the data were normally distributed or not, and to check homogeneity of the variance in data Levine test was applied. Based on the level of hamstring and lower back flexibility, players were divided into two groups i.e. High Flexibility group (HFG) and Low Flexibility group (LFG) using $\mathrm{k}$-means cluster analysis. Independent T-test was applied to find the difference in the level of agility, lower body muscular power and acceleration speed among the High Flexibility Group (HFG) and Low Flexibility Group (LFG). The level of significance was set at $\mathrm{p}<0.05$ and Statistical Package for Social Science (SPSS version 23.0, Chicago, IL, USA) was used for the analysis.

\section{Results}

In Table 1, anthropometrical variables i.e. decimal age, height and body mass are presented for all the participants and as well as HFG and LFG. Intergroup differences presented in the group shows that there were minor differences in the HFG and LFG, but these differences were not statistically significant $(p>0.05)$ that depicts that in terms of age, height and body mass there were no differences in both the groups. 
Table 1: Anthropometric characteristic of all participants $(n=84)$ and High Flexibility Group ( $\mathrm{n}=47)$ and Low Flexibility Group $(\mathrm{n}=37)$

\begin{tabular}{|l|c|c|c|c|c|}
\hline Variables & $\begin{array}{c}\text { Participants }(\mathbf{n}=\mathbf{8 4}) \\
(\text { Mean } \pm \text { SD) }\end{array}$ & $\begin{array}{c}\text { HFG }(\mathbf{n}=\mathbf{4 7}) \\
(\text { Mean } \pm \text { SD) }\end{array}$ & $\begin{array}{c}\text { LFG }(\mathbf{n}=37) \\
(\mathbf{M e a n} \pm \text { SD) }\end{array}$ & $\begin{array}{c}\text { Intergroup } \\
\text { difference }(\mathbf{\%})\end{array}$ & $\begin{array}{c}\text { p- } \\
\text { Value }\end{array}$ \\
\hline Age $($ decimal) & $16.57 \pm 1.51$ & $16.37 \pm 1.37$ & $16.83 \pm 1.65$ & $0.46(2.7)$ & .169 \\
\hline Height $(\mathrm{cm})$ & $176.23 \pm 8.77$ & $177.35 \pm 9.61$ & $174.80 \pm 7.44$ & $2.55(1.5)$ & .187 \\
\hline Body Mass $(\mathrm{kg})$ & $66.14 \pm 11.79$ & $65.39 \pm 10.38$ & $67.09 \pm 13.46$ & $1.70(2.5)$ & .514 \\
\hline
\end{tabular}

In Table 2, along with flexibility, performances of both HFG and LFG in selected test i.e. shuttle run, 20-m sprint and vertical jump with arm swing is presented. Intergroup differences between the groups are also presented for a better understanding of the results. After comparative analysis of selected variables statistically significant differences $(p<0.05)$ were observed between HFG and LFG in shuttle run, vertical jump and $20-\mathrm{m}$ sprint performances. It shows that the performance of HFG was better as compared to LFG in agility, lower body muscular power and acceleration speed.

Table 2: Comparative analysis of shuttle run, 20-m sprint and vertical jump performance of High Flexibility Group ( $n=47)$ and Low Flexibility Group $(n=37)$ of volleyball players

\begin{tabular}{|l|c|c|c|c|c|}
\hline Variables & $\begin{array}{c}\text { Participants }(\mathbf{n}=\mathbf{8 4}) \\
\text { Mean } \pm \text { SD }\end{array}$ & $\begin{array}{c}\text { HFG }(\mathbf{n}=\mathbf{4 7}) \\
\mathbf{( M e a n} \pm \text { SD) }\end{array}$ & $\begin{array}{c}\text { LFG }(\mathbf{n}=\mathbf{3 7 )} \\
\mathbf{( M e a n} \pm \text { SD) }\end{array}$ & $\begin{array}{c}\text { Intergroup } \\
\text { difference (\%) }\end{array}$ & $\begin{array}{c}\text { p- } \\
\text { Value }\end{array}$ \\
\hline Flexibility & $13.75 \pm 5.65$ & $17.81 \pm 3.42$ & $8.58 \pm 3.07$ & $9.24(107.7)$ & $<.001$ \\
\hline Shuttle Run & $15.11 \pm 0.93$ & $14.87 \pm 0.94$ & $15.42 \pm 0.84$ & $0.55(3.6)$ & .006 \\
\hline 20-m Sprint & $3.31 \pm 0.21$ & $3.27 \pm 0.20$ & $3.37 \pm 0.21$ & $0.09(2.8)$ & .039 \\
\hline Vertical Jump & $50.94 \pm 9.49$ & $53.87 \pm 9.66$ & $47.22 \pm 7.94$ & $6.66(14.1)$ & .001 \\
\hline
\end{tabular}

\section{Discussion}

The purpose of this study was to analyse the level of agility, lower body muscular power and acceleration speed among volleyball players with low and high flexibility. Flexibility training is an integral part of the total training process (Bompa, 1994) and it is very common in volleyball (Alipasali et al., 2019), but the role of flexibility on volleyball performance is not well explored. To the best of the authors' knowledge, this is the first study that assesses the role of high and low flexibility among volleyball players. In this study, it was hypothesized that volleyball players with high flexibility of hamstring and lower back may exhibit better performance in agility, acceleration speed and vertical jump as compared to the players with low hamstring and lower back flexibility.

The key findings of this study showed better performance of HFG in agility with the intergroup difference of 0.55 seconds which was $3.6 \%$ better as compared to LFG. In the case of acceleration speed, the intergroup difference was 0.09 seconds leading to $2.8 \%$ better performance in HFG. For vertical jump performance, results were highly statistically significant, where the intergroup difference was $6.66 \mathrm{~cm}$ and performance of HFG was $14.1 \%$ better than LFG. There are number of evidences available which supports the outcomes of the present study. In a study conducted on young football players, it was reported players with high levels of flexibility were better in agility, acceleration and 
sprinting and countermovement jump (García-Pinillos et al., 2015). Some other studies also agree with the outcomes of the present study (Taleb-beydokhti \& Haghshenas, 2015; Van Gelder \& Bartz, 2011). The results of these studies reported that dynamic stretching was effective to improve agility performance, which shows that improved flexibility has a positive relationship with agility performance. In the case of vertical jump performance, results were in line with Kruse et al. (2015); where they concluded that dynamic stretching significantly improved vertical jumping in female volleyball players. In another study, positive effects of stretching on jumping performance were also reported (Palaniappan \& Deivendran, 2013). In the case of acceleration speed, only one study found which supported the results of the present study, where it was reported that after six-week training, both static and dynamic stretching protocols significantly improved the performance 4.5 and $9 \mathrm{~m}$ sprint tests among recreational volleyball players (Alipasali et al., 2019). Studies also reported positive effects of active dynamic stretching on sprint performance (Alikhajeh et al., 2012; Fletcher \& Jones, 2004; Herman \& Smith, 2008). On the other hand, they also concluded that static stretching included in warm-up may decrease short sprint performance. However, Bazett-Jones et al., (2008) reported no significant improvements in sprint and vertical jump performances in female athletes after a 6-week static stretching protocol. With contradictory results of the studies, it can be concluded that the relationship of flexibility with speed is still not clear. However dynamic stretching protocol seems to be having a positive effect on the speed.

\section{Conclusions}

The results obtained from the current study shows that volleyball players with high flexibility were better in agility, acceleration speed and lower body muscular power as compared to players with low flexibility level. Based on the results it can be calculated that, for volleyball players, flexibility is a key component of training as it helps in better performance in agility, acceleration speed and vertical jump. Therefore, it is suggested that coaches and trainers should include flexibility training in the regular training programme. The results obtained support the rationale that baseline flexibility may influence the performance of volleyball players. Keeping in view the cross-sectional design of the study, which restricts to establish a causal relationship, and heterogeneous results of the previous studies, further investigations are suggested.

\section{Conflict of Interest Statement}

The authors declare no conflicts of interests.

\section{About the Authors}

Dr. Aruna Gulati, Associate Professor, Indira Gandhi Institute of Physical Education \& Sports Sciences, University of Delhi, Delhi, India. Email: aruna.gulati@igipess.du.ac.in

Dr. Rita Jain, Associate Professor, Indira Gandhi Institute of Physical Education \& Sports Sciences, University of Delhi, Delhi, India. Email: rita.jain@igipess.du.ac.in 
Dr. Anuradha Lehri, Associate Professor, Department of Sports Sciences, Punjabi University Patiala, Patiala, India. Email: anu lehri@pbi.ac.in

Rajneesh Kumar, Volleyball Coach, Netaji Subhas Southern Centre, Bengaluru, Sports Authority of India, India. Email: rajneesh.bishnoi32@gmail.com

\section{References}

Acero, R. M., Sánchez, J. A., \& Fernández-del-Olmo, M. (2012). Tests of Vertical Jump: Countermovement Jump With Arm Swing and Reaction Jump With Arm Swing. Strength and Conditioning Journal, 34(6), 87-93.

Alikhajeh, Y., Rahimi, N. M., Fazeli, K., \& Fazeli, H. (2012). The Effect of Different Warm Up Stretch Protocols on 20m-Sprint Performance in Trained Soccer Players. Procedia - Social and Behavioral Sciences, 46, 2210-2214.

Alipasali, F., Papadopoulou, S. D., Gissis, I., Komsis, G., Komsis, S., Kyranoudis, A., Knechtle, B., \& Nikolaidis, P. T. (2019). The effect of static and dynamic stretching exercises on sprint ability of recreational male volleyball players. International Journal of Environmental Research and Public Health, 16(16), 1-10.

Bazett-Jones, D. M., Gibson, M. H., \& McBride, J. M. (2008). Sprint and Vertical Jump Performances Are Not Affected by Six Weeks of Static Hamstring Stretching. The Journal of Strength \& Conditioning Research, 22(1).

Bishop, D., \& Middleton, G. (2013). Effects of static stretching following a dynamic warmup on speed, agility and power. Journal of Human Sport and Exercise, 8(2), 391-400. https://doi.org/10.4100/jhse.2012.82.07

Bompa, T. O. (1994). The Theory and Methodology of Training: The Key to Athletic Performance (O. Calcina (ed.); Third Edit). Kendall/Hunt Publishing Company.

Church, J. B., Wiggins, M. S., Moode, F. M., \& Crist, R. (2001). Effect of warm-up and flexibility treatments on vertical jump performance. Journal of Strength and Conditioning Research, 15(3), 332-336.

Cornwell, A., Nelson, A. G., Heise, G. D., \& Ben Sidaway. (2001). Acute effects of passive muscle stretching on vertical jump performance. Journal of Human Movement Studies, 40, 307-324.

Fletcher, I. M., \& Jones, B. (2004). The effect of different warm-up stretch protocols on 20meter sprint performance in trained rugby union players. Journal of Strength and Conditioning Research, 18(4), 885-888. https://doi.org/10.1519/14493.1

Gabbett, T., \& Georgieff, B. (2007). Physiological and anthropometric characteristics of Australian junior national, state, and novice volleyball players. Journal of Strength and Conditioning Research, 21(3), 902-908. https://doi.org/10.1519/R-20616.1

Gabbett, T., Georgieff, B., Anderson, S., Cotton, B., Savovic, D., \& Nicholson, L. (2006). Changes in skill and physical fitness following training in talent-identified volleyball players. Journal of Strength and Conditioning Research, 20(1), 29-35. https://doi.org/10.1519/R-16814.1 
García-Pinillos, F., Ruiz-Ariza, A., Moreno del Castillo, R., \& Latorre-Román, P. (2015). Impact of limited hamstring flexibility on vertical jump, kicking speed, sprint, and agility in young football players. Journal of Sports Sciences, 33(12), 1293-1297. https://doi.org/10.1080/02640414.2015.1022577

Greco, G., Patti, A., Cataldi, S., Iovane, A., Messina, G., \& Francesco, F. (2019). Changes in physical fitness in young female volleyball players after an 8-week in-season pilates training program. Acta Medica Mediterranea, 1, 3375-3381. https://doi.org/10.19193/0393-6384_2019_6_531

Gremion, G. (2005). The effect of stretching on sports performance and the risk of sports injury: A review of the literature. Sportmedizin Und Sporttraumatologie, 53(1), 6-10.

Hedrick, A. (2007). Training for High-Level Performance in Women's Collegiate Volleyball : Part I Training Requirements. Strength and Conditioning Journal, 29(6), 50-53.

Herman, S. L., \& Smith, D. T. (2008). Four-Week Dynamic Stretching Warm-up Intervention Elicits Longer-Term Performance Benefits. The Journal of Strength $\mathcal{E}$ Conditioning Research, 22(4).

Holmberg, P. M. (2013). Weightlifting to Improve Volleyball Performance. Strength and Conditioning Journal, 35(2), 79-88.

Johnson, T. M., Brown, L. E., Coburn, J. W., Judelson, D. A., Khamoui, A. V, Tran, T. T., \& Uribe, B. P. (2010). Effect of four different starting stances on sprint time in collegiate volleyball players. Journal of Strength and Conditioning Research, 24(10), 2641-2646. https://doi.org/10.1519/JSC.0b013e3181f159a3

Kenny, B., \& Gregory, C. (2006). Volleyball: Steps to Success. Human Kinetics.

Kerksick, C. M., Wilborn, C. D., Roberts, M. D., Smith-Ryan, A., Kleiner, S. M., Jäger, R., Collins, R., Cooke, M., Davis, J. N., Galvan, E., Greenwood, M., Lowery, L. M., Wildman, R., Antonio, J., \& Kreider, R. B. (2018). ISSN exercise \& sports nutrition review update: Research \& recommendations. Journal of the International Society of Sports Nutrition, 15(1), 1-43. https://doi.org/10.1186/s12970-018-0242-y

Kruse, N. T., Barr, M. W., Gilders, R. M., Kushnick, M. R., \& Rana, S. R. (2015). Effect of different stretching strategies on the kinetics of vertical jumping in female volleyball athletes. Journal of Sport and Health Science, 4(4), 364-370. https://doi.org/10.1016/j.jshs.2014.06.003

Lee, E. J., Etnyre, B. R., Poindexter, H. B., Sokol, D. L., \& Toon, T. J. (1989). Flexibility characteristics of elite female and male volleyball players. The Journal of Sports Medicine and Physical Fitness, 29(1), 49-51.

Little, T., \& Williams, A. G. (2006). Effects of Differential Stretching Protocols During Warm-Ups on High-Speed Motor Capacities in Professional Soccer Players. Journal of Strength and Conditioning Research, 20(1), 203-207.

Marques, M. C., Tillaar, R. Van Den, Gabbett, T. J., Reis, V. M., \& González-Badillo, J. J. (2009). Physical fitness qualities of professional volleyball players: Determination of positional differences. Journal of Strength and Conditioning Research, 23(4), 11061111. https://doi.org/10.1519/JSC.0b013e31819b78c4 
Mayorga-Vega, D., Merino-Marban, R., \& Viciana, J. (2014). Criterion-related validity of sit-and-reach tests for estimating hamstring and lumbar extensibility: A metaanalysis. Journal of Sports Science and Medicine, 13(1), 1-14.

Newton, R. U., Rogers, R. A., Volek, J. S., Hakkinen, K., \& Kraemer, W. J. (2006). Four Weeks of Optimal Load Ballistic Resistance Training at The End of Season Attenuates Declining Jump Performance of Women Volleyball Players. Journal of Strength and Conditioning Research, 20(4), 955-961.

Oldenburg, S. (2015). Complete Conditioning for Volleyball. Human Kinetics.

Palaniappan, B., \& Deivendran, V. P. (2013). Effect of Static Stretching On Vertical Jump Performance on Apparently Healthy Subjects. IOSR Journal of Nursing and Health Science, 2(2), 50-52.

Powers, M. (1996). Vertical Jump Training for Volleyball. Strength and Conditioning Journal, 18-23. https://doi.org/10.1519/1073-6840(1996)018<0018

Pradhan, K. (2017). Physical Fitness and Performance Indicators of Indian Female Volleyball Players: the Need for individual Data. Bhatter College Journal of Multidisciplinary Studies, 7(1), 1-10. https://doi.org/10.25274/bcjms.v7n1.ped-env7-01-01

Reeser, J. C., \& Bahr, R. (2003). Handbook of Sports Medicine and Science Volleyball. Blackwell Science.

Rey, E., Padrón-Cabo, A., Barcala-Furelos, R., \& Mecías-Calvo, M. (2016). Effect of High and Low Flexibility Levels on Physical Fitness and Neuromuscular Properties in Professional Soccer Players. International Journal of Sports Medicine, 37(11), 878-883. https://doi.org/10.1055/s-0042-109268

SAI. (2016). Sports Authority of India, Normative Values for Induction, Retention $\mathcal{E}$ Weeding out (G. Kishore (ed.)). Sports Authority of India.

Singh, H. (1991). Science of Sports Training. DVS Publications.

Taleb-beydokhti, I., \& Haghshenas, R. (2015). Static versus dynamic stretching Chronic and acute effects on Agility performance in male athletes. International Journal of Applied Exercise Physiology, 4(1), 1-8.

Van Gelder, L. H., \& Bartz, S. D. (2011). The Effect of Acute Stretching on Agility Performance. The Journal of Strength \& Conditioning Research, 25(11), 3014-3021.

Walsh, G. S. (2017). Effect of static and dynamic muscle stretching as part of warm up procedures on knee joint proprioception and strength. Human Movement Science, 55, 189-195. https://doi.org/10.1016/j.humov.2017.08.014

Wells, K. F., \& Dillon, E. K. (1952). The sit and reach-A Test of Back and Leg Flexibility. Research Quarterly of the American Association for Health, Physical Education and Recreation, 23(1), 115-118. https://doi.org/10.1080/10671188.1952.10761965

Young, W. B., \& Behm, D. (2003). Effects of running, static stretching and practice jumps on explosive force production and jumping performance. The Journal of Sports Medicine and Physical Fitness, 43(1), 21-27.

Ziv, G., \& Lidor, R. (2010). Vertical jump in female and male volleyball players: A review of observational and experimental studies. In Scandinavian Journal of Medicine and 
Science in Sports (Vol. 20, Issue 4, pp. 556-567). https://doi.org/10.1111/j.16000838.2009.01083.x

Creative Commons licensing terms

Authors will retain the copyright of their published articles agreeing that a Creative Commons Attribution 4.0 International License (CC BY 4.0) terms will be applied to their work. Under the terms of this license, no permission is required from the author(s) or publisher for members of the community to copy, distribute, transmit or adapt the article content, providing a proper, prominent and unambiguous attribution to the authors in a manner that makes clear that the materials are being reused under permission of a Creative Commons License. Views, opinions and conclusions expressed in this research article are views, opinions and conclusions of the author(s). Open Access Publishing Group and European Journal of Physical Education and Sport Science shall not be responsible or answerable for any loss, damage or liability caused in relation to/arising out of conflict of interests, copyright violations and inappropriate or inaccurate use of any kind content related or integrated on the research work. All the published works are meeting the Open Access Publishing requirements and can be freely accessed, shared, modified, distributed and used in educational, commercial and non-commercial purposes under a Creative Commons attribution 4.0 International License (CC BY 4.0). 